\title{
Stress assignment in polysyllabic words in Levantine Arabic: An Optimality-Theoretic analysis
}

\author{
Mohammed Nour Abu Guba \\ Faculty of Arts and Social Sciences, Sharjah University, Sharjah \\ mabu-gub@sharjah.ac.ae, Abuguba74@gmail.com
}

\begin{abstract}
Mohammed Nour Abu Guba. Stress assignment in polysyllabic words in Levantine Arabic: An Optimality-Theoretic analysis. The Poznań Society for the Advancement of Arts and Sciences, PL ISSN 0079-4740, pp. 7-24

This paper proposes an Optimality-Theoretic analysis of stress assignment in Levantine Arabic. The proposed hierarchy incorporates two constraints, namely *EXTENDED-LAPSE-R, which restricts stress to one of the last three syllables, and ALIGN-LEFT, which demands that the left edge of the prosodic word be aligned with a foot. This hierarchy is superior to earlier research as it successfully accounts for stress assignment in a more comprehensive and economical way. Most interestingly, it can account for the unexpected stress on a light penult in prosodic words ending in four light syllables and the paradoxical status of foot extrametricality without ad hoc parameterization of constraints. Moreover, findings show that footing in Levantine Arabic is iterative, an indication that secondary stress is attested in Levantine dialects.
\end{abstract}

Keywords: stress assignment, Levantine Arabic, phonology, Optimality Theory

\section{Introduction}

Although stress assignment in Arabic dialects has occupied researchers over the past fifty years, e.g. Abdo (1969), Brame (1974), Abu-Salim (1982), Hayes (1995), Adra (1999), Kager (2000), Al-Jarrah (2002), Abu-Abbas (2003), Al-Mohanna (2004) and Abu-Rakhieh (2009) (see Watson 2011 for an overview), none of them has managed to provide a satisfactory account of all cases of stress placement in polysyllabic words in Levantine Arabic (henceforth LA). ${ }^{1}$

Two main thorny cases of stress assignment have persisted in almost all attempts of stress placement in LA. The first one relates to words ending in long vowels in open syllables such as tat'tuu 'tattoo' and dara'suu 'they studies it mas.'. All previous researchers adopt final foot extrametricality to account for stressing a heavy antepenult in forms

${ }^{1}$ Levantine Arabic here refers to rural and urban dialects spoken in Jordan, Palestine, Syria and Lebanon. 
composed of heavy-light-light syllables such as 'madzzara 'massacre'. However, adopting foot extrametricality will make it difficult to successfully account for final stress in tat'tuu, as will be demonstrated in Section 2.

The second case relates to stress in prosodic words composed of four light syllables. All previous studies incorrectly predict stress to fall on the antepenult rather than the light penult as will be demonstrated in this study. In fact, previous researchers claim that such words do not exist in LA as they undergo syncope. However, a few words such as balabala 'type of food' and munu'buli 'monopoly', show that such words do exist in LA and they need to be accounted for in any comprehensive analysis of stress assignment in LA. These words pose a great challenge to previous accounts of stress in LA.

Based on stress assignment in 30 polysyllabic LA words as produced by 10 LA native speakers, the present study attempts to provide a comprehensive analysis couched within an OT framework that accounts for stress assignment in all types of words in LA without unnecessary parameterization of constraints. This paper has benefited from insights gained from the introduction of loanwords into LA dialects. ${ }^{2}$ However, due to lack of instrumental analysis of the data used in this paper, this study is meant to be a first step towards a more comprehensive account of stress in LA.

The paper is organized as follows. In Section 2, I review stress assignment in LA as laid out in previous studies and show that they cannot account for all the data. Section 3 lays out the methodology used to collect and analyze the data. Section 4 suggests an OT constraint hierarchy that avoids the problems encountered by previous research. Finally Section 5 concludes the paper.

\section{Background: Stress assignment in Levantine Arabic}

In this section, I present an overview of stress assignment as laid out in previous studies on Levantine dialects focusing on Jordanian Arabic (henceforth JA) and Palestinian Arabic (henceforth PA) and show how they fail to provide a comprehensive and accurate account of stress in LA. Focus will be on the most recent studies that adopt an OT approach, namely Al-Jarrah (2002), Abu-Abbas (2003), Mobaidin (2003), Al-Mohanna (2004) Abu-Rakhieh (2009) and Watson (2011).

All previous studies agree that stress is governed by syllable weight and syllable position such that the rightmost heavy syllable attracts stress within a three-syllable window. Syllable weight is determined by its vowel length and the presence of a coda. Following moraic theory (Hyman 1985; McCarthy \& Prince 1986; Hayes 1989), short vowels are monomoraic, while long vowels and diphthongs are bimoraic. Geminates are underlyingly moraic while non-final coda consonants are assigned a mora through the constraint WEIGHT-BY-POSITION (Hayes 1989, 1995). That is, CV syllables are monomoraic while CVV and CVC syllables are bimoraic. Onset consonants do not contribute to syllable weight at all.

\footnotetext{
2 This paper has benefited from the findings of an earlier study by the researcher (see Abu Guba 2016).
} 
Stress in LA according to previous literature would be assigned as follows. Stress falls on one of the last three syllables. The rightmost heavy syllable receives stress and if there is no heavy syllable in the word, stress falls on the first syllable with an antepenultimate limit (Brame 1974; Abu-Salim 1982; Hayes 1995; Abu-Abbas 2003; Watson 2011; among others).

The majority of previous studies adopted Hayes' (1995) formalism, given in (1), to account for stress in LA:

\section{(1) Hayes' formalism}
a. Consonant extrametricality:
$\mathrm{C} \rightarrow<\mathrm{C}>/ \ldots$ ]word
b. Foot extrametricality:
$\mathrm{F} \rightarrow<\mathrm{F}>/$ ] ]word
c. Foot construction:

\section{Form moraic trochees from left to right}
Degenerate feet are forbidden.

d. Word layer construction: End Rule Right (ERR)

The motivation for consonant extrametricality comes from the fact that CVC syllables are monomoraic and revoke stress word-finally but function as heavy and attract stress word-internally (Hayes 1995; Watson 2011; among others).

Feet in LA are moraic trochees (see Hayes 1995; Watson 2011). They are constructed from left to right. They can be composed of a heavy $(\mathrm{H})$ syllable or two light (L) syllables. HH or uneven trochees, (i.e. HL) are not allowed. Moreover, degenerate feet are absolutely forbidden. To illustrate, words composed of LLL and HLLL syllables are footed as $(\mathrm{LL}) \mathrm{L}$ and $(\mathrm{H})(\mathrm{LL}) \mathrm{L}$ respectively. End Rule Right (ERR) assigns stress to the rightmost foot.

Final-foot extrametricality was invoked to account for stress on the antepenult in words such as ('madz)zara 'massacre'. However, foot-extrametricality would wrongly predict stress not to fall on final superheavy syllables (i.e. CVVC and CVCC syllables). This made earlier analyses assume that such syllables are not in absolute final position. Following McCarthy (1979), they argue that the last consonant in these syllables intervenes between the syllable and the right edge, which deprives the syllable of peripherality. Similarly, they argue that words that end in long vowels in open syllables, as in dara'suu 'they studied it mas.' are underlyingly superheavy as they are closed by an extrametrical consonant that is deleted at the surface level cf. -naah. However, this predicts stress to fall on the initial syllable in words such as tat'tuu 'tattoo' as this word does not end in a consonant neither at the surface level nor at the underlying level. ${ }^{3}$ That is, the stressed syllable is in absolute final position and there is no extrametrical consonant that could deprive the syllable of peripherality.

Revoking extrametricality will pose other problems relating to assigning stress to, e.g. HLL forms, so we are facing a paradox here. We need foot-extrametricality to assign stress correctly to the heavy antepenult in HLL and similar forms but at the same time we need to revoke extrametricality to be able to account for stress on long vowels in final open syllables. Abu-Rakhieh (2009) attempted to circumvent this problem by positing that a heavy syllable always receives stress. However, this incorrectly predicts that

${ }^{3}$ Many words that end in long vowels in open syllables are loanwords. 
stress will fall on the preantepenult in prosodic words comprising a heavy syllable that is followed by three light syllables such as muћ'tarame 'respected fem.'.

It will be demonstrated in this study that the interaction of constraints in OT can solve this paradox. Ranking a constraint that requires heavy syllables to be stressed, namely WEIGHT-TO-STRESS PRINCIPLE (see Section 4.2.2. for definition of constraints) above NONFINALITY (extrametricality) will assign stress to heavy syllables in final position, whether an extrametrical consonant is present or not. And ranking *EXTENDED-LAPSE-R, which restricts stress to one of the last three syllables, above WEIGHT-TO-STRESS PRINCIPLE ensures that stress does not retract to a heavy preantepenult.

The second problem with previous research relates to quadrisyllabic words composed of four light syllables. All previous studies, with the exception of Abu-Salim (1982), Al-Mohanna (2004) and Watson (2011), ignored such words claiming that these words undergo syncope. However, a few words with four light syllables (e.g. balabala and munubuli) are attested in LA and they need to be included in any comprehensive analysis of stress in LA. The three researchers who dealt with such cases used a Standard Arabic word, namely fadzaratun 'tree' and claimed that it receives stress on the preantepenult. This is not satisfactory as the word is easily identified as belonging to Standard Arabic and LA native speakers could have pronounced such words according to Standard Arabic phonology, which they could have access to due to Arabic diglossia (see Suleiman 1985 for details on diglossia in Arabic). In the present study, I use colloquial words that are accessible to both literate and illiterate Arab speakers and show that such words are stressed on the penult in LA.

A third minor problem that is shared by most previous OT accounts of stress in Levantine dialects is that they resort to parameterization of constraints to make them fit their data, which is antagonistic to OT (see McCarthy \& Prince 2004). For example, Mobaidin (2003) splits NONFINALITY into two constraints: one that avoids parsing light syllables and another that avoids parsing heavy syllables while Abu-Abbas (2003) splits the EDGEMOST-R constraint (see 15 below) into two constraints: one that requires a light stressed syllable to be aligned with the right edge and another requiring a stressed heavy syllable be aligned with the right edge. This paper will suggest an OT constraint hierarchy that is able to account for all these cases in a simpler manner without ad hoc parameterization.

\section{Methodology}

A corpus of 30 polysyllabic words in LA was used to analyse stress assignment (see Appendix). These comprise 10 disyllabic words, 10 trisyllabic words and 10 quadrisyllabic and above words. All the words are common everyday words that are accessible to literate and illiterate LA speakers. The researcher did a pilot study to ensure that these words are known to illiterate people. ${ }^{4}$ He asked three illiterate LA native speakers (a Jor-

4 This is important to ensure that the words do not belong to Standard Arabic so as to preclude codemixing. 
danian, a Palestinian and a Syrian) to verify the words. All the words were known to them. ${ }^{5}$

Five male and five female monolingual native speakers of LA whose ages ranged from 30 to 50 pronounced the words in the frame sentence baguul marteen 'I say twice' three times at a natural pace. This was digitally recorded in a quiet room using a professional recorder with a built-in microphone at a $48000 \mathrm{~Hz}$ sample rate and saved in wav. format for further analysis. Table 1 presents more details about all participants. None of the participants is known for any speech disorders. The position of stress was identified impressionistically by the researcher and verified by five linguists (four LA linguists and one American linguist). The five linguists were given the list of words in IPA symbols with syllable boundaries indicated. They were asked to mark the stressed syllable in each word. Note that they could listen to the recordings as many times as they liked. Inter-rater consistency stood at $88 \%$. Note that most differences relate to non-primary stresses.

Table 1: Study participants

\begin{tabular}{|c|c|c|l|}
\hline Participant & Age & Gender & \multicolumn{1}{|c|}{ Native dialect } \\
\hline 1 & 36 & M & Rural JA/ Zarqa \\
\hline 2 & 45 & M & Urban JA Ammani \\
\hline 3 & 47 & M & Rural PA/ Bait Nabala \\
\hline 4 & 42 & M & Urban PA/ Jafa \\
\hline 5 & 33 & M & Rural SA/ Diraa \\
\hline 6 & 47 & F & Rural JA/ Zarqa \\
\hline 7 & 36 & F & Urban JA Ammani \\
\hline 8 & 50 & F & Rural PA/ Bait Nabala \\
\hline 9 & 38 & F & Urban PA/ Jafa \\
\hline 10 & 30 & F & Urban SA/ Damascene \\
\hline
\end{tabular}

\section{Results and discussion}

In this section, I present the results and suggest a constraint hierarchy within a parallel Optimality-Theoretic approach that takes all cases into account. Results confirm that stress is determined by position and weight such that stress falls on the rightmost heavy syllable within a three-syllable window. Most interestingly, it is confirmed that stress falls

${ }^{5}$ Only one word, namely balabala, was not recognized by the Syrian participant. It is kept, though, as it has four light syllables. 
on final open syllables ending in long vowels and a light penult is stressed in LLLL forms. Below I present the results in more detail.

\subsection{Stress assignment in polysyllabic words}

The following illustrative examples show stress assignment in LA according to the number of syllables.

(2) Stress assignment in LA according to number of syllables ${ }^{6}$

a) Disyllabic words

$\begin{array}{ll}\text { 'bana } & \text { 'he built' } \\ \text { 'maktab } & \text { 'office' } \\ \text { ba'naat } & \text { 'girls' } \\ \text { Pa'mall } & \text { 'more boring' } \\ \text { tat'tuu } & \text { 'tattoo' } \\ \text { dzan'naat } & \text { 'heavens' }\end{array}$

b) Trisyllabic words

$\begin{array}{ll}\text { bay'yaara } & \text { 'orchard' } \\ \text { 'madzzara } & \text { 'massacre' } \\ \text { 'fadzara } & \text { 'tree' } \\ \text { makta'baat } & \text { 'libraries' } \\ \text { dara'suu } & \text { 'they studied it mas.' }\end{array}$

c) Quadrisyllabic words and above
bala'bala
'type of food'
futu'kubi
'photocopy'
munu'buli
'monopoly game'
muћ'tarame
'respected fem.'
mistarix'yiin
'relaxed mas. pl.'
mustaffa'yaathin
'their fem. hospitals'

Results confirm that disyllabic words receive stress on the ultimate syllable iff they end in a long vowel whether closed by an extrametrical consonant or not, as in dzan'naat and tat'tuu or a short vowel closed by two consonants, as in Pa'mall. Otherwise the penult is stressed, as in 'bana and 'maktab. Note that the fact that stress falls on a final open syllable ending in a long vowel means that final feet cannot be extrametrical, as assumed earlier by previous analyses.

For trisyllabic words, again the ultimate syllable receives stress if it is heavy, ${ }^{7}$ as in dara'suu and makta'baat. Otherwise, stress falls on the penult if it is heavy, as in bay'yaara. Otherwise the antepenult is stressed regardless of its weight, as in 'madzzara

\footnotetext{
${ }^{6}$ Monosyllabic words receive stress on their only syllable, hence excluded.

${ }^{7}$ Recall that final consonants are weightless.
} 
and 'fadzara. If there is more than one heavy syllable, the rightmost syllable receives stress, as in makta'baat.

For quadrisyllabic words and above, stress assignment follows the same patterns. A heavy ultimate syllable receives stress, as in mistarix'yiin. Otherwise the penult is stressed if heavy, as in mustaffa'yaathin. However, if the penult is light and preceded by two light syllables, as in bala'bala and munu'buli, it is unexpectedly stressed. This runs counter to all previous analyses of stress in LA, which predict stress to shift leftward to the antepenult. This finding is of paramount importance to Arabic phonology and calls all previous accounts into question.

Note also that initial syllables to the left of stressed syllables are perceived to have (non-primary) stress. For example, in banaat, four linguists confirmed that both syllables are stressed. Also, in munubuli, the first and the third syllables were reported to have stress. Whether these two stresses have equal acoustic status cannot be verified impressionistically. A future study that investigates the acoustic properties of these syllables is highly recommended.

To summarize, stress in LA is restricted to a final three-syllable window where the rightmost heavy syllable receives main stress. Final heavy syllables, whether closed or open, are stressed. Moreover, a light penult (rather than the antepenult) is stressed in words composed of four light syllables. Initial syllables to the left of stressed syllables receive non-primary stress. In the following subsection, I present an OT analysis that takes all these findings into consideration.

\subsection{Theoretical analysis of stress assignment}

As shown above, findings here are similar to the findings of previous studies except for three cases. The first case relates to stressing final open syllables ending in a long vowel. The proposed analysis will account for this case by ranking a constraint that requires heavy syllables to be stressed even if they are in absolute final position without assuming that these syllables end underlyingly in a consonant that deprives the syllable of peripherality. The second case relates to HLLL forms where stress falls on the antepenult. Unlike some previous literature that cannot account for such forms (e.g. Abu-Rakhieh 2009), I will account for these cases by introducing a constraint that restricts stress to one of the last three syllables. Finally, the third case relates to stress in LLLL forms. Again, the proposed analysis accounts for these cases by introducing a constraint that requires initial syllables to be footed so as to left-align the prosodic word with a bimoraic foot.

Before embarking upon an OT analysis, I introduce very briefly the OT apparatus for readers who are not familiar with OT (for a complete introduction to OT, see Prince \& Smolensky 1993/2004; Kager 1999). 


\subsubsection{Parallel OT}

This study adopts a parallel OT framework (Prince \& Smolensky 1993/2004), which is a non-derivational theory of constraint interaction. ${ }^{8}$ OT holds that every language's grammar consists of a specific set of conflicting universal constraints, namely faithfulness and markedness constraints. Faithfulness constraints require the input and the output to be identical while markedness constraints require the output to be structurally wellformed. The mechanism (GEN) generates many candidates. These candidates are evaluated in parallel by the selection process (EVAL) using a set of ranked constraints (CON). These constraints are ranked in a strict dominance hierarchy. That is, violating a highranked constraint once is worse than violating a lower-ranked constraint multiple times. A violation mark is assigned to each form that violates a constraint. The candidate that incurs the least violations possible is the winning candidate (see Prince \& Smolensky 1993/2004; Kager 1999).

\subsubsection{OT analysis}

As we have seen, stress falls on the penult in disyllabic words comprising two light syllables, as in 'bana. Because a light syllable is monomoraic, it cannot make a foot on its own due to the undominated FOOT-BINARITY constraint, presented in (3). This necessitates parsing the final light syllable.

(3) FOOT-BINARITY (henceforth FTBIN): A foot is binary under a moraic or a syllabic level (Prince \& Smolensky 1993/2004; Hayes 1995).

Parsing the final light syllable is obligatory in order not to exhaust the stress domain (Hayes 1995; Watson 2011). Thus FTBIN must dominate a constraint that militates against parsing a final syllable, given in (4).

(4) NONFINALITY- $\sigma$ (henceforth NONFIN): The final syllable of a word is unparsed (cf. Hyde 2003).

Note that the version of NONFIN adopted here will apply to light syllables only because heavy syllables have dual status: they are syllables and bimoraic feet simultaneously (see Zec 2011: 1351). It will be shown in this section that final heavy syllables will always receive stress (cf. the constraint in (14)).

The fact that stress is assigned to the first member of the binary foot means that a foot in LA is trochaic, not iambic. This is achieved by ranking the constraint TROCHAIC in (5) over the constraint IAMBIC that assigns stress to the second member of a foot.

(5) TROCHAIC: Feet are moraic trochees (Hayes 1995; Kager 1999; Watson 2011).

The interaction of these constraints is depicted in tableau (6) for 'bana.

(6) TROCHAIC, FTBIN $>>$ NONFIN ... IAMBIC

${ }^{8}$ Although the latest advances of OT are appealing, most notably Harmonic Serialism (e.g. McCarthy \& Pater 2016), I still stick to a parallel framework of OT as it can correctly account for all my data. 


\begin{tabular}{|l|c|c|c|c|}
\hline \multicolumn{1}{|c|}{ Input: bana } & TROCHAIC & FTBIN & NONFIN & IAMBIC \\
\hline a. $r$ ('bana) & & & $*$ & $*$ \\
\hline b. (ba'na) & $* !$ & & $*$ & \\
\hline c. ('ba)na & & $* !$ & & \\
\hline
\end{tabular}

Tableau (6) establishes that FTBIN dominates NONFIN. ('bana) bests the other candidates satisfying the two top-ranked constraints. Candidate (b) has an iambic foot with stress on the second syllable and thus loses on TROCHAIC while candidate (c) is eliminated as it incurs a fatal violation of FTBIN.

The same holds true for trisyllabic words composed of light syllables only. For example, in 'fadzara, the first two light syllables group together to make a binary foot with stress on the initial syllable as per TROCHAIC. There would be no need to parse the final light syllable, which satisfies NONFIN but violates the constraint PARSE- $\sigma$ given in (7).

(7) PARSE- $\sigma$ : All syllables must be parsed into feet (Prince \& Smolensky 1993/2004).

Unparsing the final syllable shows that NONFIN dominates PARSE- $\sigma$. Consider the tableau in (8) below that lays out the interaction of these constraints yielding ('Jadza)ra.

(8) TROCHAIC, FTBIN $>>$ NONFIN $>$ PARSE- $\sigma$

\begin{tabular}{|l|c|c|c|c|}
\hline \multicolumn{1}{|c|}{ Input: Jadzara } & TROCHAIC & FTBIN & NONFIN & PARSE- $\sigma$ \\
\hline a. $($ ''fadza)ra & & & & $*$ \\
\hline b. (Ja'dza)ra & $* !$ & $* !$ & $*$ & $*$ \\
\hline c. ('fadzara) & & & $*$ & $*$ \\
\hline d. fa('dzara) & & & & \\
\hline
\end{tabular}

As the tableau shows, candidate (a) bests the other candidates as it satisfies FTBIN, TROCHAIC and NONFIN violating only the low-ranked PARSE- $\sigma$ constraint. Candidate (b) is ruled out as it fatally violates TROCHAIC and candidate (c) fatally violates FTBIN as well as NONFIN. Candidate (d) satisfies both TROCHAIC and FTBIN but loses on NONFIN.

So far, we have established the following constraint hierarchy in (9).

(9) TROCHAIC, FTBIN >> NONFIN >> PARSE- $\sigma$

Words ending in a short vowel that is closed by one consonant such as 'maktab with stress on the initial heavy syllable show that the final consonant is weightless. This violates the constraint WEIGHT-BY-POSITION, presented in (10), which assigns a mora to 
coda consonants. This means that although coda consonants contribute to weight word-internally, they are moraless in absolute final position. To account for the moraless status of absolute final consonants in LA, I adopt the constraint *FINAL-C- $\mu$ given in (11) and rank it higher than WEIGHT-BY-POSITION.

(10) WEIGHT-BY-POSITION (WBP): Coda consonants are moraic (Hayes 1989).

(11) *FINAL-C- $\mu$ : A word-final consonant is weightless (Prince \& Smolensky 1993/2004: 49; Kager 1999).

Note that the second syllable in maktab does not reject stress due to NONFIN because final heavy syllables do attract stress in LA. So it is the moraless status of the final consonant (which renders the syllable monomoraic) that is behind the stresslessness of the final syllable here.

The interaction of these two constraints is laid out in (12).

(12) *FINAL-C- $\mu>>$ WBP

\begin{tabular}{|l|c|c|}
\hline \multicolumn{1}{|c|}{ Input: maktab } & *FINAL-C- $\mu$ & WBP \\
\hline a. $\approx($ ('mak)ta<b> & & $*$ \\
\hline b. $(\mathrm{mak})($ 'tab) & $!^{*}$ & \\
\hline
\end{tabular}

Incorporating these two constraints into the hierarchy in (9), we get the following partial constraint hierarchy in (13).

(13) TROCHAIC, FTBIN, *FINAL-C- $\mu>>$ NONFIN, WBP $>>$ PARSE- $\sigma$

Note that a constraint is assumed to be undominated (top-ranked) unless contrary evidence is established so *FINAL-C- $\mu$ will be top-ranked as is the norm in OT when a constraint is first introduced. Because it is established that *FINAL-C- $\mu$ outranks WBP, the latter will be demoted below all undominated constraints even though it does not interact with them. However, because there is no interaction between NONFIN and WBP so far, they cannot be ranked with respect to each other. NONFINL dominates PARSE- $\sigma$ and therefore WBP should rank above PARSE- $\sigma$ as well.

To account for the fact that a heavy syllable within the three-syllable window receives stress, we need to adopt WEIGHT-TO-STRESS PRINCIPLE, given in (14), and rank it high in the constraint hierarchy.

(14) WEIGHT-TO-STRESS PRINCIPLE (WSP): Heavy syllables are prominent in foot structure and on the grid (Prince 1990).

Ranking WSP above NONFIN guarantees that a heavy syllable receives stress even if it is in absolute final position. However, when more than one heavy syllable is present, the rightmost heavy syllable receives stress. This is accounted for by the undominated constraint EDGEMOST(Head-F;rt;Wd) given in (15), which requires the rightmost foot to bear the primary stress. 
(15) EDGEMOST(Head-F;rt;Wd) (henceforth EDGEMOST-R): Align the head-foot of the word on the right edge (Prince \& Smolensky 1993/2004). ${ }^{9}$

Note that the other heavy syllables also receive non-primary stress. This violates a constraint that militates against adjacent stresses, namely $*$ CLASH, presented in (16), which shows that ${ }^{*} \mathrm{CLASH}$ is low-ranked in LA.

(16) *CLASH: No adjacent syllables are stressed (Kager 1999).

The interaction of these constraints is laid out in tableau (17) below.

(17) EDGEMOST-R, WSP $>>$ NONFIN $>$ PARSE- $\sigma$, *CLASH

\begin{tabular}{|l|c|c|c|c|c|}
\hline \multicolumn{1}{|c|}{ Input: dzannaat } & EDGEMOST-R & WSP & NONFIN & PARSE- $\sigma$ & *CLASH \\
\hline a. $ख(d z a n)($ 'naa) $<\mathrm{t}>$ & & & $*$ & & $*$ \\
\hline b. $($ 'dzan)(naa) $<\mathrm{t}>$ & $* !$ & & $*$ & & $*$ \\
\hline c. $($ 'dzan)naa $<\mathrm{t}>$ & & $* !$ & & $*$ & \\
\hline d. dzan('naa) $<\mathrm{t}>$ & & $* !$ & $*$ & $*$ & \\
\hline
\end{tabular}

So far we have established the following constraint ranking in (18).

(18) TROCHAIC, FTBIN, *FINAL-C- $\mu$, EDGEMOST-R, WSP $>>$ NONFIN, WBP $>>$ PARSE- $\sigma$, *LASH

The above constraints cannot account for longer words with a heavy syllable that is not within the three-syllable window, as in muћ'tarame. According to the above constraints, WSP will opt for the preantepenult; however, the attested form in LA has stress on the light antepenult. So we need a constraint that ranks higher than WSP to prevent stress from retracting to the heavy preantepenult.

Note that although a form of NONFIN and EDGEMOST-R (Prince \& Smolensky 1993/2004) would correctly account for stress in HLLL forms, it cannot be adopted as it fails to account for stress in LLLL forms, as will be demonstrated below. The same applies to LAPSE (Gordon 2002) or LAPSE-2 (Kager 1999), which militates against unparsing two consecutive syllables because they cannot account for LLLL cases as they predict stress to fall on the antepenult. Moreover, LAPSE/LAPSE-2 cannot account for the antepenultimate stress in HLL forms where stress falls on the heavy antepenult leaving two syllables unparsed..$^{10}$ Note further that an attempt to assume that WSP is an undominated constraint (e.g. Abu-Rakhieh 2009) to ensure that stress falls on a heavy syllable in ultimate position also fails as it would predict stress to retract to the heavy preantepenult.

9 This constraint is identical to the alignment constraint ALIGN (Head-F;rt;Wd).

${ }^{10}$ Recall that earlier analyses (e.g. Hayes 1995; Abu-Abbas 2003; Abu-Rakhieh 2009) resorted to foot-extrametricality to account for HLL forms. 
That being the case, we still need to rank WSP high in the constraint hierarchy, but at the same time we need another constraint that ranks higher than WSP to ensure that stress does not retract to the heavy preantepenult. To solve this paradox, following Gordon (2002) and Kager (2012), I adopt the constraint *EXTENDED-LAPSE-R given in (19) below and rank it higher than WSP, which would prevent stress from retracting to the preantepenult.

(19) *EXTENDED-LAPSE-R: No more than two unstressed syllables occur between the stress and the right word edge (Gordon 2002; Kager 2012).

*EXTENDED-LAPSE-R ensures that stress is confined to one of the last three syllables in a prosodic word. This constraint is similar to Hyde's (2008) WINDOW-FINAL constraint, which requires stress to fall on a three-syllable window at the right edge (for more details, see Hyde 2008).

To illustrate, in words with a heavy preantepenult such as muћ'tarame, stress falls on the peninitial light syllable violating WSP. Stress cannot fall on the preantepenult as this will incur a fatal violation of *EXTENDED-LAPSE-R. Footing proceeds from left-toright constructing a bimoraic foot over the first heavy syllable (so it receives a non-primary stress) and another bimoraic foot over the antepenult and the penult. Given that there are two feet, stress falls on the rightmost foot as dictated by EDGEMOST-R. There would be no need to parse the final syllable, which violates PARSE- $\sigma$ but satisfies NONFIN. Consider the tableau in (20) that incorporates *EXTENDED-LAPSE-R and demotes WSP below *EXTENDED-LAPSE-R.

(20) *EXTENDED-LAPSE-R, EDGEMOST-R, FTBIN $>$ WSP $>$ NONFIN $>>$ PARSE- $\sigma$

\begin{tabular}{|c|c|c|c|c|c|c|}
\hline Input: muhtarame & $\begin{array}{l}* \text { EXTEND- } \\
\text { ED-LAPSE-R }\end{array}$ & $\begin{array}{l}\text { EDGEM- } \\
\text { OST-R }\end{array}$ & FTBIN & WSP & $\begin{array}{l}\text { NON- } \\
\text { FIN }\end{array}$ & PARSE- $\sigma$ \\
\hline a. (muh)('tara)me & & & & & & $*$ \\
\hline b. ('muh)tarame & $* !$ & & & & & $* * *$ \\
\hline c. muh('tara)me & & & & $* !$ & & $* *$ \\
\hline d. (muћta)('rame) & & & $* !$ & & * & \\
\hline
\end{tabular}

As the tableau shows, stress is assigned to the light antepenult as it cannot retract to the heavy preantepenult, thanks to *EXTENDED-LAPSE-R, which must dominate WSP. Note that candidate (a) does not violate WSP as the heavy syllable is footed and consequently receives non-primary stress.

To recapitulate, a heavy syllable is assigned stress if it is within the three-syllable window; otherwise, stress falls on the light antepenult. If there is more than one heavy syllable within the stress window, the rightmost syllable receives stress.

Now let us turn to quadrisyllabic words with no heavy syllables, as in bala'bala. Such words have been ignored in previous studies on LA dialects because these words are not 
very common in LA as most of them undergo syncope (see Kager 2007 for other Arabic dialects). However, the proposed analysis in this study can account for all the data including such words economically and comprehensively.

According to the constraints presented so far and according to previous studies (cf. Section 2), stress would fall on the antepenult yielding the unattested *ba'labala. To correctly account for stress on the light penult in such cases, I adopt the constraint ALIGNLEFT (Prwd, F) given in (21), which demands that the left edge of the prosodic word be aligned with a foot.

(21) ALIGN-LEFT (Prwd, F) (henceforth ALIGN-L): Every prosodic word begins with a foot (Kager 1999: 169; Gordon 2011).

This constraint is different from the constraint ALL-FFET-LEFT, which was adopted in earlier studies (e.g. Al-Jarrah 2002; Mobaidin 2003). ALL-FEET-LEFT requires all feet in a word to be aligned with the left edge of the word. Violations are counted by the number of syllables that separate each foot from the left edge. That is, it is satisfied only if one foot is constructed at the left edge. In this study I argue that not only does LA require footing to be left to right, but it also requires prosodic words to start with a foot, which must be bimoraic according to FTBIN. In fact, ALL-FEET-LEFT does not always guarantee that footing starts with the first syllable. For example, in LLLL forms footing would be rightward but can start with the second syllable ignoring the first syllable. This is how earlier analyses parsed forms with a light syllable that is followed by a heavy syllable such as banaat yielding ba('naa) $<\mathrm{t}>$. They assumed that the first stranded syllable is adjoined as a weak member to the prosodic word (e.g. Abu-Salim 1982).

The interaction of these constraints is depicted in tableau (22) below, which shows the evaluation of the word /balabala/ > bala'bala.

(22) *EXTENDED-LAPSE-R, EDGEMOST-R, ALIGN-L, FTBIN >> NONFIN >> PARSE- $\sigma$

\begin{tabular}{|c|c|c|c|c|c|c|}
\hline Input: balabala & $\begin{array}{c}\text { *EXTENDED- } \\
\text { LAPSE-R }\end{array}$ & EDGEMOST-R & ALIGN-L & FTBIN & NONFIN & PARSE- $\sigma$ \\
\hline a. (bala)('bala) & & & & & $*$ & \\
\hline b. ('bala)(bala) & & *! & & & * & \\
\hline c. ba('laba)la & & & $* !$ & & & $* *$ \\
\hline d. ('bala)bala & $* !$ & & & & & $* *$ \\
\hline e. bala('bala) & & & $* !$ & & $*$ & $* *$ \\
\hline f. (bala)('ba)la & & & & $* !$ & & $*$ \\
\hline
\end{tabular}

As can be seen from tableau (22), stressing the antepenult in (22c) incurs a fatal violation of ALIGN-L while the optimal candidate in $(22 \mathrm{a})$ satisfies all constraints except 
for the low-ranked NONFIN. ALIGN-L enforces parsing the initial light syllable, which cannot make up a foot on its own. This requires parsing the second light syllable to make up a bimoraic foot to satisfy the undominated FTBIN. We are left with two unparsed light syllables at the right edge, which is attested in LA, albeit marked. However, this cannot be optimal as stress would incorrectly fall on the preantepenult, which incurs a fatal violation of the undominated *EXTENDED-LAPSE-R constraint. Therefore, the first two syllables make up a bimoraic foot that is left-aligned with the prosodic word and the phonological string is further scanned and the last two syllables group together to construct a bimoraic foot violating only NONFIN. EDGEMOST-R selects the rightmost foot and stress falls on the light penult.

Note that there is no need for an independent constraint that requires footing to proceed from left to right as suggested by some earlier researchers (e.g. Al-Jarrah's (2002) ALL-FFET-LEFT). In fact, the interaction of ALIGN-L and NONFIN ensures that foot directionality is rightward in LA. This will render the analysis more economical. ALLFEET-LEFT would be needed to account for a hypothetical form such as HLLLL. Here the directionality of footing is crucial as leftward footing would assign stress to the antepenult yielding $(\mathrm{H}) \mathrm{L}(\mathrm{LL}) \mathrm{L}^{11}$ while rightward footing would assign stress to the penult yielding $(\mathrm{H})(\mathrm{LL})(\mathrm{LL})$. Given that such forms are not attested in LA at all, I do without ALL-FFET-LEFT.

To recap, ranking ALIGN-L and *EXTENDED-LAPSE-R above NONFIN yields the optimal output (bala)('bala). No interaction between *EXTENDED-LAPSE-R, ALIGN-L and EDGEMOST-R has been observed so no ranking relationships can be established and they will be equally ranked.

One might argue against the introduction of ALIGN-L as some words in LA seem to violate it. For example, in banaat, stress falls on the heavy ultimate syllable leaving behind a monomoraic light syllable that cannot make a foot on its own as per FTBIN. That is, the output is not left-aligned with a foot. Although this seems to be a logical conclusion, following Abu Guba (2016), I argue that this is not the case. Abu Guba (2016), based on the adaptation of English loanwords in Arabic, demonstrates that ALIGN-L is high ranked in Arabic and the cases which seem to violate it on the surface do satisfy it underlyingly and the only words that do violate ALIGN-L are derived words such as na.xiil 'palm trees', and fa.baab 'young people' and the vowel in these monomoraic initial syllables is the short low vowel /a/. ${ }^{12}$ This means that morphologically complex words violate ALIGN-L as they could need to satisfy a high-ranked constraint that requires morphological templates in Arabic morphology to be mapped faithfully in the output (see Abu Guba 2016 for more arguments in favor of ALIGN-L). ${ }^{13}$

\footnotetext{
${ }^{11}$ Recall that ALIGN-L ensures that the first syllable is footed and NONFIN ensures that the last syllable is unparsed.

${ }_{12}$ This vowel is also phonetically different in that it is more sonorous and longer than the other two short vowels in LA, namely /i/ and /u/.

${ }^{13}$ ALIGN-L and FTBIN are assumed to be equally ranked although ALIGN-L is violated in polymorphemic words. This is because ALIGN-L in polymorphemic words is violated to satsify templatic morphological constraints rather than FTBIN.
} 
In the same vein, prosodic words that have a light syllable that is followed by a heavy stressed syllable were usually perceived as having two stresses by the five linguists who verified the corpus of this study. For example, bannat was reported to have two stresses by four out of the five linguists (cf. Appendix).

All in all, ALIGN-L appears to be an underrepresented constraint in LA that has been ignored in previous literature. The introduction of this constraint renders the analysis simpler and more parsimonious.

\section{Conclusion}

This paper has proposed a constraint hierarchy, presented in (23), that is better able to account for stress assignment in LA.

(23) *EXTENDED-LAPSE-R, EDGEMOST-R, ALIGN-L, TROCHAIC, FTBIN, *FINAL-C- $\mu>$ WSP, WBP » NONFIN $>>$ PARSE- $\sigma,{ }^{*} \mathrm{CLASH}$

This hierarchy is superior to previous work in LA as it accounts for stress assignment in a simpler and more economical way. It is also more explanatorily adequate as it does without unnecessary parameterization, thanks to the ranking relationships that were established between the suggested constraints.

It has been shown that an analysis that adopts NONFINALITY- $\sigma$ is more descriptively adequate from a phonological perspective as it can capture all the data without ad hoc parameterization of constraints. This was achieved by sandwiching NONFIN between PARSE- $\sigma$ on the one hand and FTBIN and WSP on the other. That is, NONFIN was violated only to satisfy WSP (which ensures that heavy syllables receive stress in absolute final position) and FTBIN (in order not to exhaust the stress domain). Adopting syllable-nonfinality rather than foot-nonfinality seems to be more adequate, which awaits further evidence from future studies that could apply this analysis on other Arabic dialects and other languages.

Moreover, the introduction of ALIGN-L, which could represent an underrepresented constraint in LA, has informed the analysis and rendered it more comprehensive, thanks to the introduction of loanwords that provided new challenging input that stimulated latent constraints (Abu Guba 2016). In a similar vein, results show that footing in LA is iterative and feet are constructed from left to right with main stress on the rightmost foot and non-primary stresses on the other feet.

The introduction of *EXTENDED-LAPSE-R has accounted for a universal tendency where stress is restricted to a three-syllable window at the right edge. As we have seen in Section 4.2.2., neither the interaction between EDGEMOST-R and NONFIN nor LAPSE-2 can prevent stress from retracting to the preantepenult.

Most interestingly, it has been found, contrary to all previous studies, that LA stresses a light penult in LLLL forms. This results from the interaction of *EXTENDED-LAPSE-R and ALIGN-L yielding an output that is less marked where all the syllables are parsed into two bimoraic feet. 
A future study that investigates stress place in polysyllabic words acoustically is highly recommended. This would provide further evidence for the findings of this study.

\section{Acknowledgments}

I would like to thank Professor Janet Watson and Professor Stuart Davis for their feedback on earlier versions of this paper. Thanks are also due to the participants for providing me with the data and to my colleagues at Sharjah University for verifying the recordings.

Appendix: Words used and stress assignment as perceived by the 5 linguists and the researcher (words 1-10 are disyllabic; 11-20 - trisyllabic; 21-30 - quadrisyllabic and above)

\begin{tabular}{|c|c|c|c|c|c|c|c|c|}
\hline & \multirow{2}{*}{ Target word } & \multirow{2}{*}{ Gloss } & \multicolumn{5}{|c|}{ Linguist } & \multirow{2}{*}{ 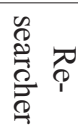 } \\
\hline & & & 1 & 2 & 3 & 4 & 5 & \\
\hline 1 & ba.na & 'he built' & $1^{*}$ & 1 & 1 & 1 & 1 & 1 \\
\hline 2 & mak.tab & 'office' & 1 & 1 & 1 & 1 & 1 & 1 \\
\hline 3 & ba.naat & 'girls' & $2 / 1^{* *}$ & $2 / 1$ & $2 / 1$ & $2 / 1$ & 2 & $2 / 1$ \\
\hline 4 & saa.Yaat & 'watches' & $2 / 1$ & $2 / 1$ & $2 / 1$ & $2 / 1$ & $2 / 1$ & $2 / 1$ \\
\hline 5 & dzan.naat & 'heavens' & $2 / 1$ & $2 / 1$ & $2 / 1$ & $2 / 1$ & 2 & $2 / 1$ \\
\hline 6 & Pa.mal & 'hope' & 1 & 1 & 1 & 1 & 1 & 1 \\
\hline 7 & Pa.mall & 'more boring' & 2 & 2 & $2 / 1$ & 2 & 2 & 2 \\
\hline 8 & dzaam.9a & 'university' & 1 & 1 & 1 & 1 & 1 & 1 \\
\hline 9 & tat.tuu & 'tattoo' & $2 / 1$ & $2 / 1$ & $2 / 1$ & 2 & 2 & $2 / 1$ \\
\hline 10 & Pa.buu & 'his father' & 2 & $2 / 1$ & $2 / 1$ & 2 & 2 & $2 / 1$ \\
\hline 11 & ba.la.dak & 'your mas. country' & 1 & 1 & 1 & 1 & 1 & 1 \\
\hline 12 & madz.za.ra & 'massacre' & 1 & 1 & 1 & 1 & 1 & 1 \\
\hline 13 & fa.dza.ra & 'tree' & 1 & 1 & 1 & 1 & 1 & 1 \\
\hline 14 & ba.ga.raat & 'cows' & $3 / 1$ & 3 & $3 / 1$ & $3 / 1$ & 3 & $3 / 1$ \\
\hline 15 & say.ya.raat & 'cars' & $3 / 1$ & $3 / 1$ & $3 / 1$ & $3 / 1$ & 3 & $3 / 1$ \\
\hline 16 & da.ra.suu & 'they studied it mas.' & $3 / 1$ & $3 / 1$ & 3 & 1 & 3 & $3 / 1$ \\
\hline 17 & da.ras.na & 'we studied' & 2 & 2 & $2 / 1$ & 1 & 1 & $2 / 1$ \\
\hline 18 & fa.baab.na & 'our youth' & $2 / 1$ & 1 & $2 / 1$ & 2 & 2 & $2 / 1$ \\
\hline 19 & mak.ta.baat & 'libraries' & $3 / 1$ & $3 / 1$ & 3 & 3 & $3 / 1$ & $3 / 1$ \\
\hline 20 & bay.yaa.ra & 'orchard' & 1 & $2 / 1$ & $2 / 1$ & 2 & $2 / 1$ & $2 / 1$ \\
\hline 21 & fa.dza.raat.na & 'our trees' & $3 / 1$ & $3 / 1$ & 3 & $3 / 1$ & $3 / 1$ & $3 / 1$ \\
\hline 22 & da.ras.naa.ha & 'we studies it fem.' & $3 / 1$ & $3 / 1$ & $3 / 1$ & $3 / 2$ & $3 / 2$ & $3 / 1$ \\
\hline 23 & bi.ka.dil.li & 'Piccadilly' & $3 / 1$ & $3 / 1$ & $3 / 1$ & $3 / 1$ & $3 / 1$ & $3 / 1$ \\
\hline 24 & ba.la.ba.la & 'type of food' & $3 / 1$ & $3 / 1$ & $3 / 1$ & $3 / 1$ & $3 / 1$ & $3 / 1$ \\
\hline 25 & fu.tu.ku.bi & 'photocopy' & $3 / 1$ & $3 / 1$ & $1 / 3$ & $3 / 1$ & $3 / 1$ & $3 / 1$ \\
\hline
\end{tabular}




\begin{tabular}{|l|l|l|c|c|c|c|c|c|}
\hline 26 & mu.nu.bu.li & 'monopoly game' & $3 / 1$ & $3 / 1$ & $1 / 3$ & $3 / 1$ & $3 / 1$ & $3 / 1$ \\
\hline 27 & ti.li.ta.biz & 'teletubbies show' & $3 / 1$ & $3 / 1$ & 1 & $3 / 1$ & $3 / 1$ & $3 / 1$ \\
\hline 28 & muh.ta.ra.me & 'respected fem.' & $2 / 1$ & $2 / 1$ & $2 / 1$ & $2 / 1$ & $2 / 1$ & $2 / 1$ \\
\hline 29 & mis.ta.rix.yiin & 'relaxed mas. pl.' & $4 / 1$ & $4 / 1$ & $4 / 1$ & $4 / 1 / 3$ & $4 / 1$ & $4 / 1 / 3$ \\
\hline 30 & mus.taf.fa.yaat.hin & 'their fem. hospitals' & $4 / 1$ & $4 / 1$ & $4 / 1$ & $4 / 1 / 2$ & $4 / 1$ & $4 / 1 / 2$ \\
\hline
\end{tabular}

* This refers to the number of the stressed syllable among the ten participants. That is, 1 means that the first syllable was stressed according to the first linguist.

** The second/third numbers refer to non-primary stresses. This means that the second syllable in this word has primary stress while the first syllable was perceived to have non-primary stress by this linguist.

\section{References}

Abdo, Daoud. 1969. Stress and Arabic phonology. University of Illinois. (Doctoral dissertation.)

Abu-Abbas, Khaled. 2003. Topics in the phonology of Jordanian Arabic. University of Kansas. (Doctoral dissertation.)

Abu Guba, Mohammed Nour. 2016. Phonological Adaptation of English Loanwords in Ammani Arabic. Salford University. (Doctoral dissertation.)

Abu-Rakhieh, Belal A. 2009. The phonology of Ma'ani Arabic: Stratal or parallel OT. University of Essex. (Doctoral dissertation.)

Abu-Salim, Issam. 1982. A reanalysis of some aspects of Palestinian Arabic: A metrical approach. University of Illinois. (Doctoral dissertation.)

Adra, Mohammed. 1999. Identity effects and opacity in Syrian Arabic: An Optimality Theory analysis. University of Illinois at Urbana-Champaign.) (Doctoral dissertation.)

Al-Jarrah, Rasheed. 2002. An optimality-theoretic analysis of stress in the English of native Arabic speakers. Ball State University. (Doctoral dissertation.)

Al-Mohanna, Faisal. 2004. Paradoxical non-finality: Stress assignment in three Arabic dialects.| Retrieved Feb 2014, from http://roa.rutgers.edu/files/735-0505/735-AL-MOHANNA-0-1.PDF.

Brame, Michael K. 1974. The Cycle in phonology: Stress in Palestinian, Maltese, and Spanish. Linguistic Inquiry 5(1). 39-60.

Gordon, Matthew. 2002. A factorial typology of quantity insensitive stress. Natural Language and Linguistic Theory 20. 491-552.

Gordon, Matthew. 2011. Stress systems. In Goldsmith, John A. \& Riggle, Jason \& Yu, Alan C.L. (eds.), The handbook of phonological theory, 2nd edition, 141-163. Oxford: Wiley-Blackwell.

Hayes, Bruce. 1989. Compensatory lengthening in moraic phonology. Linguistic Inquiry 20. 253-306.

Hayes, Bruce. 1995. Metrical stress theory: Principles and case studies. Chicago: University of Chicago Press.

Hyde, Brett. 2003. NonFinality. Ms, Washington University in St Louis. Retrieved Sep 2014 from http://roa. rutgers.edu/files/633-1103/633-HYDE-0-0.PDF.

Hyde, Brett. 2008. Alignment continued: distance sensitivity, order sensitivity and the midpoint pathology. Rutgers Optimality Archive, ROA \#998-1108.

Hyman, Larry M. 1985. A theory of phonological weight. Dordrecht: Foris.

Kager, René. 1999. Optimality Theory. Cambridge University Press.

Kager, René. 2000. Surface opacity of metrical structure in Optimality Theory. In Hermans, Ben \& van Oostendorp, Marc, (eds), The Derivational Residue in Phonology, 207-245. Amsterdam: John Benjamins. [ROA-207, http://ruccs.rutgers.edu/roa.html]

Kager, René. 2007. Stress. In Versteegh, Kees \& Eid, Mushira \& Elgibali, Alaa \& Woidich, Manfred \& Zaborski, Andrzej (eds.), Encyclopaedia of Arabic language and linguistics, 4, 344-353. Leiden: Brill.

Kager, René. 2012. Stress in windows: Language typology and factorial typology. Lingua 122(13). 1454-1493.

McCarthy, John J. 1979. On stress and syllabification. Linguistic Inquiry 10. 443-465.

McCarthy, John J. \& Pater, Joe. 2016. Harmonic grammar and harmonic serialism (Advances in Optimality Theory). London: Equinox Publishers. 
McCarthy, John J. \& Prince, Alan. 1986. Prosodic morphology. MS., Brandeis University.

McCarthy, John J. \& Prince, Alan. 2004. The emergence of the unmarked. In McCarthy, John J., Optimality Theory in phonology: A reader, 483-494. Oxford: Blackwell.

Mobaidin, Hussam. 2003. Prosodic prominence in Jordanian Arabic. Mu'tal Lil-Buhuth wad-Dirasat 18(2). 99-125.

Prince, Alan. 1990. Quantitative consequences of rhythmic organization. In Deaton, Karen \& Noske, Manulela \& Ziolkowski, Michael (eds.), CLS 26(2): Papers from the Parasession on the Syllable in Phonetics and Phonology, 355-398. Chicago: Chicago Linguistic Society.

Prince, Alan \& Smolensky, Paul. 1993/2004. Optimality Theory: Constraint interaction in generative grammar. Technical Report CU-CS-696-93, Department of Computer Science, University of Colorado at Boulder, and Technical Report TR-2, Rutgers Centre for Cognitive Science, Rutgers University, New Brunswick, NJ.

Suleiman, Saleh. 1985. Jordanian Arabic between diglossia and bilingualism: Linguistic analysis. Amsterdam: John Benjamins.

Watson, Janet C. E. 2011. Word stress in Arabic. In van Oostendorp, M. \& Ewen, C. \& Hume, E. \& Rice, K. (eds.), The Blackwell companion to phonology, 2990-2918. Malden, MA, Oxford: Wiley-Blackwell.

Zec, Draga. 2011. Quantity-sensitivity. In van Oostendorp, Marc \& Ewen, Collin J. \& Hume Elizabeth \& Rice Keren (eds.), The Blackwell companion to phonology, 1335-1361. Malden, MA, Oxford: Wiley-Blackwell. 